\title{
Cyanosis as Mortality Risk among Children with Severe Pneumonia
}

\author{
Herza Fadlinda, ${ }^{1}$ Adi Utomo, ${ }^{2}$ Henni Djuhaeni ${ }^{3}$ \\ ${ }^{1}$ Faculty of Medicine Universitas Padjadjaran, ${ }^{2}$ Department of Child Health, Faculty of Medicine \\ Universitas Padjadjaran/Dr. Hasan Sadikin General Hospital Bandung, ${ }^{3}$ Department of Public \\ Health Medicine Faculty of Medicine Universitas Padjadjaran
}

\begin{abstract}
Background: Pneumonia is the second leading cause of infant death in Indonesia. The mortality of pneumonia in children is associated with cyanosis, malnutrition, and age less than 4 months. The aim of this study was to determine the relationship between cyanosis, malnutrition, and age less than 4 months with the mortality of infant patients with severe pneumonia at Dr Hasan Sadikin General hospital.

Methods: A case-control study has been conducted using medical records of 80 patients with pneumonia at Dr. Hasan Sadikin General Hospital, period January 2007 to December 2013. The inclusion criteria were medical records consisting of information about infants with severe pneumonia, without comorbid diagnoses, who died during hospitalization. While controls were infants who have been discharged from hospital. The independent variables of this study were cyanosis, malnutrition, and age less than 4 months, while the dependent variable was the mortality. Data were analyzed by using univariate and bivariate analysis.

Results: The study reported that only cyanosis was associated with mortality. Malnutrition and age less than 4 months were not associated with mortality.

Conclusions: Cyanosis is known to be the only factor that has affected the mortality of infants with pneumonia who are hospitalized at Dr. Hasan Sadikin General Hospital. [AMJ.2016;3(2):186-9]

Keywords: Children, cyanosis, pneumonia
\end{abstract}

\section{Introduction}

Pneumonia stands for lung tissue-damaging inflammation caused by atypical infectious agents such as M. pneumoniae, C. pneumoniae and L. pneumophila. . $^{1,2}$ According to the World Health Organization (WHO), severe pneumonia in children is indicated by chest indrawing. Pneumonia kills many children under-five with an annual incidence of 150.7 million cases worldwide. ${ }^{3}$ Incidence of pneumonia in Southeast Asia's children is really high. ${ }^{4}$ In 2013, theprevalence of pneumonia in Indonesia was $4.5 \%$. According to the Indonesian Health Demographics Survey in 2009, West Java Province had a high incidence of pneumonia of more than $4 \% .{ }^{5}$

Neonatal deaths areascribed to 3 major causes: premature birth, sepsis, and pneumonia. ${ }^{6}$ Pneumonia is deemed to be responsible for the loss of lives at least in 2 million children annually $20 \%$ of all child deaths) with $70 \%$ of all deaths occuring in Africa and Southeast Asia. ${ }^{7}$ High incidence of deaths among children under-five are associated with many factors, e.g. cyanosis, hepatomegaly, inability to eat, malnutrition, mental status changes, prolongation of sickness duration, comorbid chronic diseases, and age less than 4 months. ${ }^{8,9}$ Those associations have been confirmed by multiple studies abroad however, in Indonesia, particularly in West Java, such associations are still open to dispute. The high incidence of deaths among children under-five due to pneumonia and lack of studies investigating the validity of the above-mentioned associations become the background of this study. The objective of this study was to investigate the influence of cyanosis, malnutrition, and age of less than 4 months on death among children with severe pneumonia. The fore-mentioned factors were chosen as research variables because the data were always recorded in thepatient's medical 
Table 1 Frequency of Cyanosis, Malnutrition, and Age of Less than 4 Months among Cases and Controls

\begin{tabular}{lccccc}
\hline \multirow{2}{*}{ Risk Factors } & & \multicolumn{4}{c}{ Patient Category } \\
\cline { 3 - 6 } & & Case $(\mathrm{n}=4)$ & $(\%)$ & Control $(\mathrm{n}=40)$ & $(\%)$ \\
\hline Cyanosis & Yes & 7 & 17.5 & 1 & 2.5 \\
\multirow{3}{*}{ Malnutrition } & No & 33 & 82.5 & 39 & 97.5 \\
\multirow{3}{*}{ Age less than 4 months } & Yes & 25 & 62.5 & 21 & 52.5 \\
& No & 15 & 37.5 & 19 & 47.5 \\
& Yes & 6 & 15 & 4 & 10 \\
& No & 34 & 85 & 36 & 90 \\
\hline
\end{tabular}

records while other factors e.g. hepatomegaly, mental status changes, comorbid chronic diseases, and inability to eat were rarely recorded.

Hopefully, the results of this study could aid clinicians in formulating prognosis for children with severe pneumonia. This study should also provide greater details on clinically deteriorating factors among children with severe pneumonia.

\section{Methods}

This study had employed a case-control study design utilizing medical records of pediatric in patients with severe pneumonia at Dr. Hasan Sadikin General Hospital from January 2007 to December 2013. The cases in this study were pediatric inpatients who died of severe pneumonia, while control patients were also pediatric in patients with severe pneumonia but were later discharged.

The samples were medical records of pediatric patients who fulfilled the inclusion criteria. The inclusion criteria in this study for thecase group was complete medical records consisting of information about patients with severe pneumonia who had been treated at the Department of Pediatrics of Dr. Hasan Sadikin General Hospital from January 2007 to December 2013; maximum age of 5 years; and had died, meanwhile the inclusion criteria for the control group was similar to the case group however the patients werelater discharged. The implemented exclusion criteria were medical records consisting ofinformation about pediatric inpatients with comorbidities. The simple randomized sampling was used and the study eventually involved 80 patients who were divided into equal groups of cases and controls.

The data were then subjected to a chisquared statistical test. All the statistical calculations were executed using statistics software

\section{Results}

The results of this study were presented in tables displaying the frequency of the risk factors among patients and the relationship between each risk factor and mortality.

Table 1 demonstrates that cyanosis was only rarely encountered among the study population as only a meager $10 \%$ of the population reported such finding. Of such lean number, the majority of cyanosis was encountered in those who died of pneumonia (cases). Patients with malnutrition were higher in number than those without but the difference in their numbers was not significant. Only a few of the patients included in the study

Table 2 Relationship between Cyanosis and Mortality

\begin{tabular}{lcccccc}
\hline \multirow{2}{*}{ Cyanosis } & \multicolumn{5}{c}{ Mortality } & \multirow{2}{*}{ P-value* } \\
\cline { 2 - 6 } & \multicolumn{3}{c}{ Yes (n=40) } & \multicolumn{2}{c}{ No (n=40) } & \\
\cline { 2 - 6 } & 7 & f & \% & f & \% & 0.025 \\
\hline Yes & 7 & 17.5 & 1 & 2.5 & \\
No & 33 & 82.5 & 39 & 97.5 & \\
\hline Note: *Chi-squared test & & & & & &
\end{tabular}


Table 3 Relationship between Malnutrition and Mortality

\begin{tabular}{|c|c|c|c|c|c|}
\hline \multirow{3}{*}{ Malnutrition } & \multicolumn{4}{|c|}{ Mortality } & \multirow{3}{*}{ P-value* } \\
\hline & \multicolumn{2}{|c|}{ Yes $(n=40)$} & \multicolumn{2}{|c|}{ No $(n=40)$} & \\
\hline & f & $\%$ & $\mathbf{f}$ & $\%$ & \\
\hline Yes & 25 & 62.5 & 21 & 52.5 & 0.366 \\
\hline No & 15 & 37.5 & 19 & 47.5 & \\
\hline
\end{tabular}

Note: ${ }^{*}$ Chi-squared test

were less than 4 months old and out of the few, the case patients contributed more than the control patients (15\% against $10 \%)$.

Furthermore, theChi-squared test was then used to analyze the relationship between cyanosis and children mortality. A p-value of 0.025 established that the hypothesis of a relationship between cyanosis and mortality among children with pneumonia was significant.

The Chi-squared test was also used to analyze the relationship between malnutrition and mortality among children. A p-value of 0.366 failed to establish any significant association and the hypothesis of malnutrition influencing mortality was not significant.

A p-value of 0.499 failed to establish such influence and the hypothesis of such young age having an influence on mortality was not significant.

\section{Discussion}

According to Djelantik et al. ${ }^{9}$ and Lutala et al. $^{10}$, age of less than 4 months and cyanosis [95\% CI, $0.21(0.10-0.42), p$-value $=0.00]$ are associated with deaths among patients with pneumonia. Deaths due to pneumonia can be reduced by strict attention to the forementioned risk factors. ${ }^{4}, 10$ This study has investigated the association between cyanosis and deaths among children with pneumonia and the statistical analysis revealed that such association in fact existed among patients at Dr. Hasan Sadikin General Hospital which wasproven by the $p$-value of 0.025 .
A different finding was reported concerning the child's age. A p-value $>0.05$ between age of less than 4 months and mortality among children suggested that the two variables lack definitive association. Such finding might have been due to the limited number of patients of such age being referred to and treated at Dr. Hasan Sadikin General Hospital. This finding was also at odds with the current data that mortality due to pneumonia among children under-five in Indonesia was still high. Future studies with larger populations involving multiple centers are deemed necessary to produce more accurate findings.

Moreover, Scott et al. ${ }^{12}$ revealed in their study that mortality due to pneumonia could be lessened by improvements in nutrition. Meanwhile, Caulfield et al. ${ }^{13}$ who demonstrated that poor nutrition was responsible for many pneumonia deaths also confirmed such revelation. Another study in India performed by Ghimire et al. ${ }^{14}$ four years ago demonstrated that malnutrition has increased the proportion of deaths among patients with pneumonia. In addition, according to Divyarani et al. ${ }^{11}$, low birth weight among children under-five is also associated with pneumonia. ${ }^{11-14}$ However, all of these findings were at odds with the findings of this study. According to the data, no significant relationship could be established between malnutrition and mortality among pediatric inpatients at Dr. Hasan Sadikin General Hospital. Such finding could have been due to malnutrition being so widespread among both case and control patients and this presented a potential bias that may corrupt the findings of

Table 4 Relationship between Age Less than 4 Months and Mortality

\begin{tabular}{|c|c|c|c|c|c|}
\hline \multirow{3}{*}{ Age less than 4 months } & \multicolumn{4}{|c|}{ Mortality } & \multirow{3}{*}{ P-value* } \\
\hline & \multicolumn{2}{|c|}{ Yes $(n=40)$} & \multicolumn{2}{|c|}{ No $(n=40)$} & \\
\hline & f & $\%$ & f & $\%$ & \\
\hline Yes & 6 & 18 & 4 & 10 & 0.499 \\
\hline No & 34 & 85 & 36 & 90 & \\
\hline
\end{tabular}

Note: ${ }^{*}$ Chi-squared test 
this study. On one side, malnutrition presents itself as a risk factor but on the other side, it may also act as a comorbidity that worsens the prognosis of a child with pneumonia. In some way, a study performed by Yudhi et al. ${ }^{15}$ in the province of West Nusa Tenggara resonated with this study's findings as they revealed in 2010 that most pediatrics patients with pneumonia under their care actually had normal nutritional status. ${ }^{15}$

In conclusion, cyanosis has a significant association with mortality among children with pneumonia at Dr. Hasan Sadikin General Hospital. Both malnutrition and age of less than 4 months show no such association.

This study though is not without limitations. Lack of sample is attributable to the mostly incomplete data and sometimes lost medical records. Thus, it is suggested that further studies should pay close attention to the confounding factors, such as comorbidities, geographic location, completeness of medical records, and study methods. In addition, better computerization of the medical records should be pursued to minimize both the inaccuracies and the losses of medical records at Dr. Hasan Sadikin General Hospital.

\section{References}

1. Kending C. Disorders of the respiratory track in children. 8th ed. China: Elsevier saunders; 2012.

2. Ngeow YF, Suwanjutha S, Chantarojanasriri T, Wang F, Saniel M, Alejandria M, et al. An Asian study on the prevalence of atypical respiratory pathogens in communityacquired pneumonia. Int J Infect Dis. 2005;9(3):144-53.

3. Rudan I, Tomaskovic L, Boschi-Pinto C, Campbell H. Global estimate of the incidence of clinical pneumonia among children under five years of age. Bull World Health Organ. 2004;82(12):891-970.

4. Turner C, Turner P, Carrara V, Burgoine K, Htoo STL, Watthanaworawit W, et al. High rates of pneumonia in children under two years of age in a South East Asian refugee population. PLoS One. 2013;8(1):e54026.

5. Weber, Handy F. Situasi pneumonia balita di Indonesia. Buletin Jendela Epidemiologi.
2010;3(1):1-10.

6. Bryce J, Shibuya K, Boschi-Pinto C, Black RE. WHO estimates of the causes of death in children. Lancet. 2005;365(9465):114752.

7. Singh V. The burden of pneumonia in children: an Asian perspective. Paediatr Respir Rev. 2005;6(2):88-93.

8. Narayanan M, Falade AG. Clinical risk factor for death in children with pneumonia. Australia: International Child Health Review Collaboration; 2006 [Cited 2015 May 6]; Available from: http://www.ichrc. org/sites/default/files/riskpneumo.pdf.

9. Djelantik IG, Gessner BD, Sutanto A, Steinhoff M, Linehan M, Moulton LH, et al. Case fatality proportions and predictive factors for mortality among children hospitalized with severe pneumonia in a rural developing country setting. J Trop Pediatr. 2003;49(6):327-32.

10. Lutala PM, Suzgo M, Maurice M, Raphael T, Eric K. Pneumonia in rural Malawians under five years old: treatment outcomes and clinical predictors of death on admission. Afr J Prim Health Care Fam Med. 2009;1(1):112-7.

11. Divyarani DC, Patil GR, Ramesh K. Profile on risk factors of pneumonia among under-five age group at a tertiary care hospital. Int J Curr Microbiol Appl Sci. 2014;3(6):750-4.

12. Scott JA, Brooks WA, Peiris JS, Holtzman D, Mulholland EK. Pneumonia research to reduce childhood mortality in the developing world. J Clin Invest. 2008;118(4):1291-300.

13. Caulfield LE, de Onis M, Blössner M, Black $\mathrm{RE}$. Undernutrition as an underlying cause of child deaths associated with diarrhea, pneumonia, malaria, and measles. Am J Clin Nutr. 2004;80(1):193-8.

14. Ghimire M, Bhattacharya SK, Narain JP. Pneumonia in South-East Asia Region: public health perspective. Indian J Med Res. 2012;135(4):459-68.

15. Yudhi Kurniawan, Sang Ayu Kompyang Indriani. Karakteristik pasien pneumonia di ruang rawat inap anak Rumah Sakit Umum Provinsi Nusa Tenggara Barat. CDK. 2012;39(3):196-7. 